\title{
Food and Nutrition Policies of African Countries
}

\author{
Thimba Lurch $^{1}$, Thabanu Rhushine ${ }^{1}$, Nyoki Shimpiwe ${ }^{1}$ \\ ${ }^{1}$ Department of Human Nutrition, University of Pretoria, South Africa
}

\begin{abstract}
The food crisis that is currently being faced by the world is very vulnerable to the survival of mankind. A food crisis usually begins with a shock to either supply or demand for food and often involves a sudden spike in food prices. Food security is a flexible concept that is reflected in many attempts at every definition used in research and policy. Empowerment of farmers in the African agricultural sector is the key to realizing African food security. The strategy of privatizing agricultural inputs by prohibiting the circulation of traditional seeds indirectly forces small farmers to buy private agricultural inputs.
\end{abstract}

Keywords: Food Crisis, Food and Nutrition Policy, Food Security

Received: July 9, 2021

Revised: August 15, 2021

Accepted: August 29, 2021

\section{Introduction}

As a worldwide problem, the food crisis now requires the immediate attention of all international players. In order to ensure the quality of life of the global community, each country must begin implementing alternative ways to achieve national food security in order to achieve national food security. This is necessary in light of the fact that the dangers faced by the globe are no longer simply focused on conventional security concerns such as war and conflict, but also on problems that have a direct effect on human existence, such as environmental degradation. The globe is presently experiencing a food crisis that is very dangerous to the existence of humanity.

As a result, it is anticipated that every player and nation would be attentive to food security policy. The food crisis, which has affected many nations across the globe, is a worldwide problem that continues to exist in the present day (Petersen, 2003). As a result, nations facing a food crisis are forced to think creatively in order to find a solution. The world's population is still suffering from acute hunger, which affects as many as 842 million people worldwide. The term "severe hunger" refers to a situation in which a person is suffering from hunger or a food crisis, which makes it difficult for the general public to engage in regular and healthy activities and activities that promote health. According to the findings of the Food and Agriculture Organization of the United Nations (FAO), as many as 36 nations were affected by a food crisis.

This tendency may be seen starting with the threat of a food crisis and progressing to an issue of human security. Because there are many factors contributing to the significant rise in food costs, finding a solution will not be simple. The rise in energy costs has put a burden on every step of the food manufacturing process. Governments across the globe started to worry as a result of rising commodity prices, which served as a smack in the face to those who believed that limiting exports to other nations would only make matters worse for their citizens. An very severe drought struck the Horn of Africa region of East Africa in 2011, affecting Somalia, Ethiopia, and Kenya amongst other nations. These nations are experiencing severe food shortages in their respective areas. There are more than 13 million people in the Horn of Africa who need emergency food aid, in addition to inhabitants of Los Angeles and Berlin. It is located 
in the Horn of Africa. Famine is a term used to describe a period of extreme hunger and food shortages that happened in East Africa during 2011 and 2012. Africa, which includes nations such as Somalia. Famine in East Africa is a natural occurrence, but the issue is exacerbated by the ongoing war in the region. As a result of the ongoing conflict in Somalia, which has lasted for years, there is a food crisis in the country that is only becoming worse after four years of famine in the country. According to the United Nations (UN), Africa is once again confronted with a food crisis as a result of rare rains, increasing food costs, and the continuation of a dangerous security situation.

\section{Food and Nutrition Crisis Concept}

Food crises occur if there is a significant increase in hunger and malnutrition on a local, national, or international scale (Holt Giménez \& Shattuck, 2011; Timmer, 2010). It is important to note that this definition separates food crises from chronic hunger, despite the fact that food crises are far more likely to occur in communities who have previously experienced protracted hunger and malnutrition. A food crisis is often triggered by a shock to either the supply or demand for food, and it is frequently accompanied by a sharp increase in the price of food. Food security is a conceptually fluid term, as shown by the many efforts at defining it that have been made in study and policy (Himmelgreen \& Romero-Daza, 2010). At the 1996 World Food Summit, participants agreed on a more complicated definition: Food security is achieved when all people, at all times, have physical and economic access to adequate and safe food that is nutritious and meets their dietary needs and food preferences for an active and healthy lifestyle (Pérez-Escamilla, 2017).

The idea of food security goes back to the mid-1970s, when it was discussed in the context of worldwide food problems during the global food crisis (Fernández-Wulff, 2013). Priorities were first given to problems of food supply and guaranteeing the availability of basic foods, as well as some degree of price stability in the case of staple foods on an international and national scale. It is this supply-side set of international and institutional issues that is mirrored in the organization's approach to the economy, namely the changes that have resulted from the global food crisis it has caused. A series of international discussions ensued, culminating in the 1974 World Food Conference and the establishment of a new set of institutional arrangements, which included information, resources to improve food safety, and a platform for discussion of policy problems, among other things. Protecting fundamental freedoms - liberties that are at the heart of human existence - is essential to human security. The protection of individuals from critical (severe) and pervasive (widespread) dangers and circumstances is essential. This entails using procedures that capitalize on people's existing abilities and ambitions. This entails establishing political, social, environmental, economic, and military cultural systems, as well as assisting individuals in earning their livelihoods and determining their own dignity in order to ensure their long-term viability.

It is important to note that the notion of food security is an interconnected system, and as such, it is composed of three major subsystems. These are the availability of foods, the distribution of foods, and the consumption of foods. Food distribution covers the distribution of food that must be delivered in an equal and equitable manner (Coley et al., 2009). On top of that, reasonable food prices for the community, people, and families must be available in conjunction with food distribution programs. As a result, the food distribution subsystem strives to guarantee food accessibility while also maintaining food price stability. In addition, the Food Consumption Subsystem involves measures to raise public knowledge of good nutrition and to keep food costs under control so that individuals may fulfill their nutritional requirements while still being able to purchase food at an acceptable price. Because the 
economy is the primary source of food insecurity, when individuals cannot afford to purchase food or the price of food is out of reach for the majority of the population.

\section{Urgency of Food and Nutrition Policy}

Developing Food Security and Nutrition Systems in a Systematic Way is Very Important As the global food security development trajectory shifts in a path that combines food security and nutrition security approaches, strategic strategies in the fields of national food security and nutrition should adapt to this new orientation for a variety of reasons, including the following: First and foremost, the issue of nutrition in Africa, which arises as a result of the current state of food and nutrition security, continues to be very severe. A high prevalence of stunting (short and very short stature in children under two years of age), obesity in children under five and adults, micronutrient deficiencies (lack of vitamin A, iron deficiency anemia, and disorders due to iodine deficiency), and an increasing prevalence of the disease characterize this condition. noncommunicable disease (PTM) caused by a poor community food consumption pattern First and foremost, the incidence of dietary disorders and PTM is still very prevalent. Because of limited purchasing power and limited access to food, this condition is related to the underlying problems, which include relatively low quality (composition and safety) of available food, poor physical and environmental conditions, and a lack of access to food both physically and economically (access to clean water, hygiene and sanitation). Poor parenting as a consequence of a lack of education and awareness, as well as restricted access to health-care services are all factors to consider.

As a result of the above, the development of food and nutrition security in Africa in the future will need a systems approach in order to facilitate cross-sectoral development connections and the achievement of synergies across sectors via cross-sectoral coordination. This cooperation may be accomplished via the Food Security Council, which is an independent organization. To stimulate food production, political stability must be maintained, fair international and domestic trade must be implemented, and the quality of infrastructure and technology must be improved so that it not only increases food production but also reduces food loss at the level of farmers, traders, and distributors, as well as at the level of individual households.

\section{Food Utilization}

Increasing the effectiveness of food and nutrition institutions Participation of all interested parties is encouraged (government, local government, legislative institutions, business actors, philanthropists, NGOs, media, academics and research institutions as well as civil society at the center and regions). The fact that more than 800 million people worldwide are still suffering from hunger and chronic malnutrition, despite the fact that the world has advanced tremendously in terms of infrastructural development and technological sophistication, is a sobering reality. In Africa, the rate of hunger is mostly concentrated on the continent, with more than 23 percent of the continent's population suffering from hunger at any one time. It has become a global priority, with the G8 nations agreeing to establish a public-private international collaboration group called the New Alliance for Food Security and Nutrition to address the problem of hunger and food insecurity (NAFSN) 


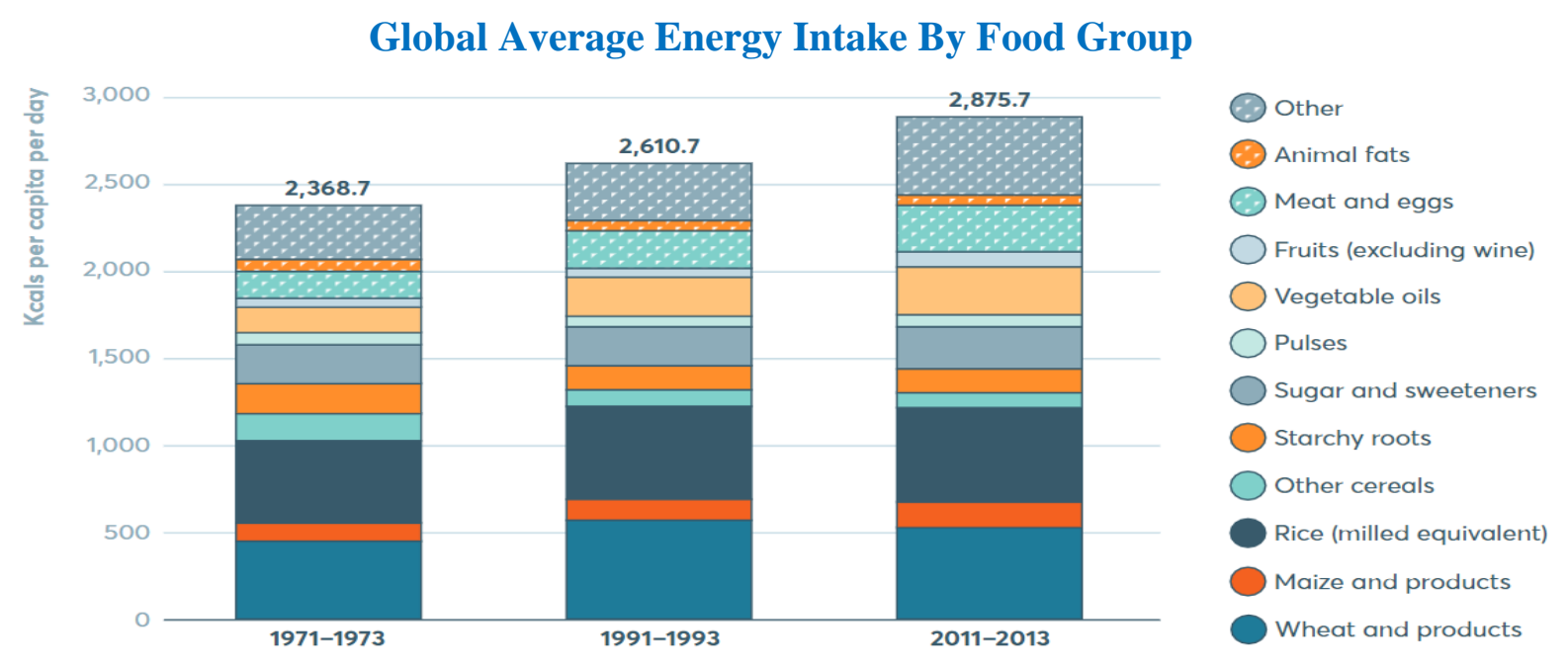

Source: Prabhu Pingali, 2015. Agricultural policy and nutrition outcomes - getting beyond the preoccupation with staple grains. Food Security

Figure 1. Global Average Energy Intake By Food Group

\section{Food and Nutrition Policy in African Countries}

When the state and the private sector agree to work together contractually in the process of financing, planning, implementation, operation, and maintenance of infrastructure and services in the public sector, they may do tasks that would otherwise be performed by the government. The North American Food Security Network (NAFSN) was formally established during the Camp David Summit in 2012 to address food and poverty issues, particularly on the African continent. The National Agricultural and Food Security Network (NAFSN) aspires to raise 50 million Africans out of poverty and hunger by 2020 via agricultural investment and policy changes. The National African Food Security Network (NAFSN) thinks that investing in agriculture is the key to solving hunger issues in Africa, since agriculture is both a food producer and an income source for the continent's people. A total of three main actors participate in this collaboration: the governments of African countries serving as host countries, G-8 member countries serving as donor countries and development partners, and the private sector, which includes Multinational Corporations (MNCs) engaged in agriculture such as Wilmar International, Yara, Unilever, Monsanto, and Cargill, among others.

Also encouraged is a change in national policy on seeds and agricultural inputs, which approves the prohibition of informal distribution of locally grown seeds between farmers and requires the cultivation of seeds that have been developed in accordance with the standards of agricultural sector corporations. Small farmers will be burdened by this policy since they will have to raise the cost of acquiring agricultural inputs, while African farmers, who account for 90 percent of the population, would be unable to purchase certified seeds from private producers due to a lack of purchasing power. The Alliance for Food Security in Africa (AFSA), whose head is Million Belay, has warned that the implementation of the NAFSN would be disastrous for small African farmers. Million Belay is the leader of the group. The African Federation for Social Development (AFSA) has accused NAFSN of becoming a new wave of colonialism in Africa. According to the American Farm Bureau Federation, a variety of measures, such as seed privatization and tax laws, are more lucrative for corporations than for small farmers. 
In the NAFSN, the main issues discussed include land use policies that make it easier for corporations to control land and thereby force small farmers from their land in Africa, tax reduction policies for corporations, privatization of agricultural inputs, and the use of genetically modified agricultural inputs that pollute the environment and pose a threat to environmental health. African cuisine is diverse. Associations of African youth and students who are members of ADECRU in African nations are vocal in their opposition to the execution of the NAFSN and demand for a stop to the implementation of the collaboration.

Poverty and poor productivity are intertwined concepts. Poverty leads in a lack of savings, which in turn results in less investment. Because of a lack of financial and capital assistance to develop industrial activities, low investment leads in poor productivity. If productivity is low, the labor force level is also low, which results in low income or poverty once again. Food security may be achieved by providing additional responsibilities in the agriculture sector other than private sector investment as capital owners. Agriculture and the economy that are more oriented toward market forces, together with trade liberalization, have the potential to produce a more competitive market, thus encouraging more foreign direct investment in developing nations. In order to create a more competitive market and more favorable conditions for investors, all obstacles that hinder market competition and result in low product quality must be removed. In this case, the government plays a role in providing policies that encourage investment while also dereglementing policies that have been obstacles in the previous years. in the process of market liberalization It is based on five major methods to achieving food security in Africa, which include, among other things, the implementation of NAFSN: Agricultural input competition is supported by policies and regulations that encourage the private sector to enter the agricultural input market; land use rights and systems are reformated; trade in agricultural products is liberalized; credit access in the agricultural sector is increased; and support for the Multi-Sectoral Nutrition Act is provided.

\section{Implementing Policy Changes}

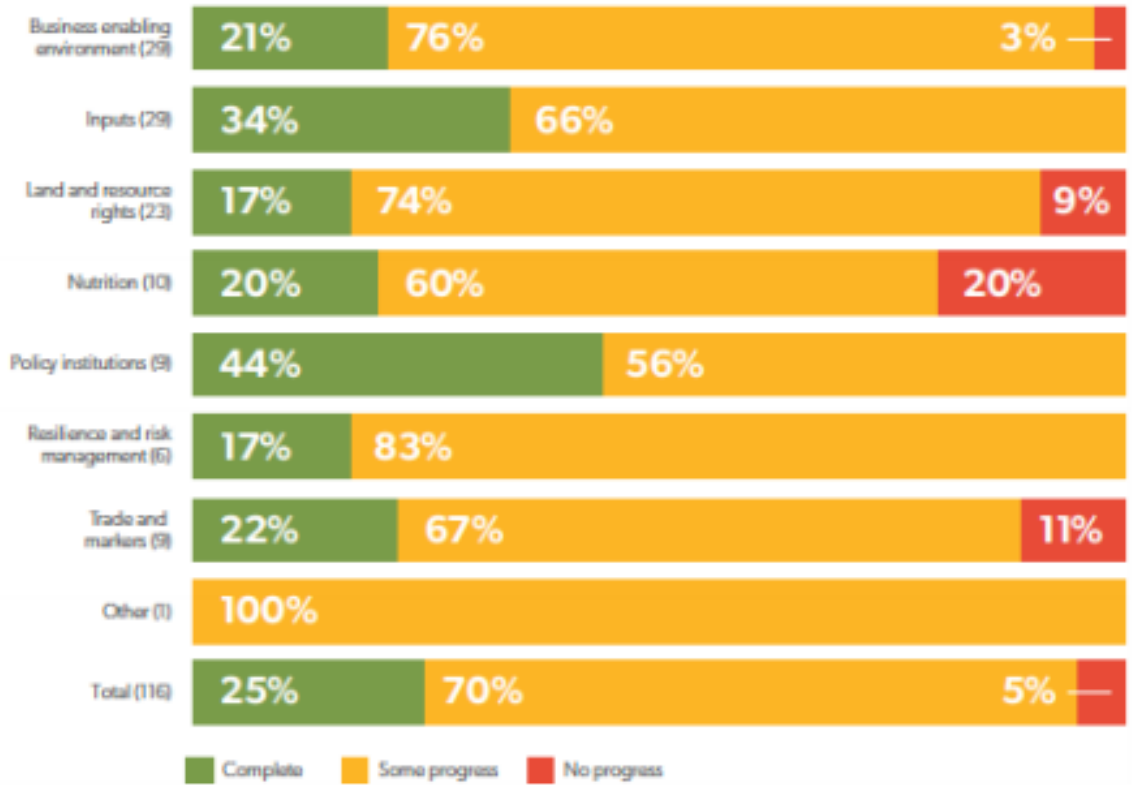

Source: G8 New Allience for food security and Nutrition, Progress report

Figure 2. State of Progress in Implementing Policy Changes

Participating organizations' commitment is emphasized. It is estimated that development partners would contribute a total of USD 6.2 billion to assist the national action plans for food 
security in the 10 participating countries over the next five years. The donors have released USD 2.1 billion, or about 72 percent of the pledges they had made as of June 2014, according to the United Nations Development Programme. Engagements from the private sector The ten countries involved had 180 companies sign 'Letters of Intent (LoIs)' promising to invest a total of USD 8 billion in agriculture; although private investors were initially slow to deliver (only USD 60 million was invested in 2012 under the LoI), approximately USD 1.1 billion in investment had been made by the end of 2013. According to a rough estimate, this investment reaches approximately 1.90 million smallholders (21 percent of whom are women), including through service provision (546,947 farmers), procurement from these producers (208 935 farmers), participation in outside smallholder schemes (11194 farmers), and training (593 481 farmers). 17; and that they have resulted in the creation of 36,676 new employment directly or indirectly (40 percent of which are women). In general, the commitments stated in the LoI have been followed through on: by mid-2014, the New Alliance estimated that 78 percent of investments made had been completed ahead of schedule (13 percent) or as planned (38 percent), or had encountered few problems or delays, according to the New Alliance (24 percent ). 18 However, while some African-based companies play a significant role in the NAFSN (as measured by the estimated size of the investments pledged in the 'Letters of Intent' included in the New Alliance Country Cooperation Framework), two companies stood out as having made significant contributions: Swiss seed company Syngenta and Norwegian fertilizer company Yara International (which pledged USD 500 million and USD 1.5 billion, respectively) and Swiss fertilizer company Syngenta.

As many as four policies in the field of agricultural inputs have been completed so far, with the next most completed policies in the field of improving nutrition, where two out of three policies have been completed, and the most recently completed policy in the field of trade liberalization, where one out of two policies has been completed. The policy on land use rights, as well as the policy on financial support for farmers, are the two areas of emphasis that are currently being completed. The private sector, which includes both local and international businesses who engage in agriculture in Africa, is the second important player in the NAFSN. It plays a major role in promoting agricultural investment in Africa. Smallholders in Africa have a duty to invest in agriculture, and the private sector has a responsibility to do so on the basis of a letter of intent.

Privatization, export-oriented investment, and agricultural modernisation are the three methods used by the NAFSN to achieve food security in Africa. Privatization can be defined in a variety of ways, including: involving the private sector in the provision of services or facilities that are typically the responsibility of the public sector; the shift from publicly produced goods and services to privately produced goods and services; and the process of transferring government functions or assets to private companies.

In order for privatization to be successful, there must be a private sector with the necessary money and technological capabilities. This is what gives rise to the benefits of privatization, which include giving financial aid or support to a program's execution by the government, as well as speeding program implementation via the use of more creative approaches and superior technological capabilities. Privatization, on the other hand, has several disadvantages, including the existence of a profit-oriented private sector that will result in a trade monopoly, the dominance of the private sector will reduce the control and power of the government, and the free market system and private sector competition will destabilize the economy of marginalized communities, among other things. Several measures are taken by NAFSN to execute a privatization plan for inputs and agricultural land. The first of these activities is deregulation of policies that encourage private inputs. The second action is deregulation of 
policies that promote private land ownership. According to the NAFSN cooperation in Africa, the government is committed to facilitating the entry of agricultural inputs from the private sector through the implementation of a national seed policy that prohibits the distribution of uncertified seeds obtained from traditional cultivation and prohibits the free exchange of seeds except in emergency situations, while allowing the private sector to import seeds. Without certification, seeds refer to seeds that have historically been grown by farmers and are the product of a previous year's crop that have been kept and shared among relatives within a community.

To encourage private investment and production in agricultural inputs, the government also enacts proprietary laws that protect privately developed high-yielding seed types in order to encourage private investment and production in agricultural inputs Establish and execute a national fertilizer policy that aims to enhance the use of fertilizers in the agricultural sector. In order to improve the quality of agricultural food production in Africa, this plan will provide high-quality agricultural inputs, such as certified superior seeds and chemical fertilizers, to the continent's agricultural producers. The prohibition on the distribution of conventional seeds will increase the demand for better seeds from the private sector, which will in turn increase the supply.

The reform of land use rights is the second step in the commercialization of agriculture. When it comes to land use rights, the government is dedicated to changing the system, which is known in Portuguese as the Direito de Uso e Aproveitamento dos Terras (DUAT), which translates as "right of use and profit of land." As part of this commitment, several steps are taken, such as developing procedures to obtain land use rights in rural areas for the agribusiness industry that are as time and cost efficient as possible and developing regulations that allow communities to work together in the area of land leasing and leasing agreements (G8 New Alliance for Food Security and Nutrition t.t). According to Articles 109 and 111 of the African Constitution of 2004, the state has complete authority over all land in Africa. There are three ways in which an individual or community can obtain land use rights: 1) Rural communities have permanent land use rights to control land under customary law; 2) Individuals can control land through the use of 'good faith,' which means that they have managed the land for at least 10 years; and 3) Individuals or companies can apply for land use rights in a specific area for a period of 50 years wihout having to pay a fee.

\section{Conclusion}

The empowerment of farmers in the African agricultural sector is critical to the achievement of food security on the continent. Small farmers are forced to purchase commercial agricultural inputs as a result of the policy of privatization agricultural inputs, which includes banning the circulation of indigenous seeds. Farmers' incomes and buying power, on the other hand, remain at a low level, notwithstanding the recent improvement. Agricultural operations by smallholders would be disrupted if they do not have access to other options besides purchasing private agricultural inputs in an environment of limited economic capacity and purchasing power. Dispossession led to accumulation, which resulted in proletarianization, which is the process by which farmers were divorced from their property rights in the means of production such as land and degraded into wage labor. It is the NAFSN's proletarianization policy, which prohibits small farmers from using or distributing traditional seeds, that contributes to the process of proletarianization. 


\section{References}

Coley, D., Howard, M., \& Winter, M. (2009). Local food, food miles and carbon emissions: A comparison of farm shop and mass distribution approaches. Food policy, 34(2), 150155.

Davies, B. B., \& Hodge, I. D. (2007). Exploring environmental perspectives in lowland agriculture: AQ methodology study in East Anglia, UK. Ecological economics, 61(23), 323-333.

Fernández-Wulff, P. (2013). International trade and food security: can agrobiodiversity reconcile both. United Nations Peace and Progress, 1(1), 18-32.

Himmelgreen, D. A., \& Romero-Daza, N. (2010). Eliminating "hunger" in the US: Changes in policy regarding the measurement of food security. Food and Foodways, 18(1-2), 96113.

Holt Giménez, E., \& Shattuck, A. (2011). Food crises, food regimes and food movements: rumblings of reform or tides of transformation?. The Journal of peasant studies, 38(1), 109-144.

Holt Giménez, E., \& Shattuck, A. (2011). Food crises, food regimes and food movements: rumblings of reform or tides of transformation?. The Journal of peasant studies, 38(1), 109-144.

Magdoff, F. (2008). The world food crisis. Monthly Review, 60(1), 1-15.

Pérez-Escamilla, R. (2017). Food security and the 2015-2030 sustainable development goals: From human to planetary health: Perspectives and opinions. Current developments in nutrition, 1(7), e000513.

Petersen, P. E. (2003). The World Oral Health Report 2003: continuous improvement of oral health in the 21st century-the approach of the WHO Global Oral Health Programme. Community Dentistry and oral epidemiology, 31, 3-24.

Sahoo, P. (2006). Foreign direct investment in South Asia: Policy, trends, impact and determinants. think-asia.org

Timmer, C. P. (2010). Preventing food crises using a food policy approach. The Journal of nutrition, 140(1), 224S-228S 